\title{
Accelerated environmental degradation and residual flexural analysis of carbon nanofiber reinforced composites
}

\author{
Steven Eric Zeltmann, Ronald L. Poveda and Nikhil Gupta ${ }^{*}$
}

Composite Materials and Mechanics Laboratory

Department of Mechanical and Aerospace Engineering

Polytechnic School of Engineering, New York University, Brooklyn, NY 11201

Phone: 646-997 3080, Email: ngupta@nyu.edu

\begin{abstract}
Hollow particle filled composites known as syntactic foams presently find numerous applications in structures exposed to high moisture and high temperature environments. Carbon nanofiber (CNF) reinforcement is attractive in these composites because of the possibility of increased strength with negligible density variation. In the present study, syntactic foams containing 15-50 vol.\% glass microballoons (GMB) and 1-5 wt.\% CNF reinforcement as well as CNF/epoxy composites containing 1-5 wt.\% CNF were exposed to accelerated weathering by immersion in $90^{\circ} \mathrm{C}$ water for two weeks and characterized for their residual flexural properties. In the worst performing composites, a maximum weight gain of $3.5 \%$ and $10 \%$ was observed for CNF/epoxy and $\mathrm{CNF} /$ syntactic foam composites, respectively. The syntactic foams tested were observed to generally decrease in strength after weathering with the exception of the composites containing 5 wt.\% CNF and 15 vol.\% GMB, which were observed to increase in strength by $41-51 \%$ after
\end{abstract}

\footnotetext{
${ }^{*}$ Corresponding author.
} 
weathering. The composite containing 5 wt.\% CNF was also shown to increase in strength by $27 \%$ after weathering. Strength retention is attributed to the presence of CNF, along with competing weathering effects on composite structure and morphology.

Keywords: Polymer matrix composite; nanocomposite; carbon nanofiber; syntactic foam; moisture degradation

\section{INTRODUCTION}

Syntactic foams are hollow particle filled composite materials which, in the present work, consist of glass microballoons (GMBs) dispersed in an epoxy resin matrix. Syntactic foams are used in marine and aerospace applications [1-3], where these materials may be exposed to high moisture content including total immersion for their entire working life at temperature extremes [4, 5]. The matrix, matrix-particle interface and hollow particles may interact with water and may have their own degradation mechanisms affecting the properties of syntactic foams over short and long term exposures [6-9]. Therefore, understanding of the moisture absorption characteristics and degradation mechanisms of these composites is critical for existing and potential future applications.

A comprehensive literature review of environmental degradation of syntactic foams is presented in a recent publication [7]. A variety of studies are now available on the effect of moisture and temperature on syntactic foams, which include studies on the tensile and compressive properties after moisture exposure [4, 10-15]. Other environmental studies performed on syntactic foams have included analysis of residual flexure properties $[6,10,16]$, thermal/electrical conductivity 
$[2,5,8]$, permittivity [17-19], and dynamic mechanical properties [9]. Syntactic foams reinforced with an additional phase have been characterized in several existing studies [20]. Most of the available literature has focused on GMB reinforced syntactic foams. It is observed that the commonly used sodalime borosilicate particles may degrade due to dealkalization in contact with water [7]. Sufficient degradation of GMB walls due to dealkalization can open up the porosity enclosed inside them for moisture accumulation. Particles are the major load bearing elements in the material under compression $[21,22]$, therefore, their degradation leads to severe reduction in compressive properties. One of the additional effects of such degradation is that the particlematrix interface is also severely degraded, such that the strength and modulus of the overall composite are observed to decrease [7]. Moisture effects on plain syntactic foams have been studied at high temperature, where several additional factors are found to contribute to the degradation of syntactic foams [12]. It is observed that the thermal expansion of the matrix at high temperature can also increase the moisture uptake because of reduced resistance to moisture diffusion in the polymer. The mismatch in the coefficient of thermal expansion of matrix and particle material can result in high thermal stresses and rapid degradation of the particle-matrix interface.

Reinforcement of syntactic foams with fibers is of great interest to improve their tensile and flexural properties. Extensive work has been performed in the field of polymer matrix nanocomposites [23-25], which can be exploited to improve the properties of syntactic foams. The inclusion of carbon nanofiber (CNF) reinforcement in syntactic foams [26-29] has been recently explored because small quantities of CNFs added to syntactic foams can greatly enhance their mechanical properties $[3,30,31]$. A rich body of literature is available on the degradation 
of carbon nanocomposites [32-35] but few have studied nano-reinforced syntactic foams. The moisture degradation of CNF reinforced syntactic foams has been studied at room temperature for long-term water immersion [7]. Evidence of particle degradation was detected in that study and reduction in mechanical properties was also noted. In epoxy and vinyl ester matrix syntactic foams under flexural loading, brittle fracture begins on the tensile side of the specimen. Thus, the flexural properties of syntactic foams show a stronger dependence on the matrix resin properties and are less sensitive to the wall thickness of the particle. Reinforcement of the matrix with fibers can improve the flexural properties of syntactic foams. In the present work, CNF reinforced syntactic foams (referred to as $\mathrm{CNF} /$ syntactic foams) are exposed to accelerated weathering through immersion in water at $90^{\circ} \mathrm{C}$ for a period of two weeks. The GMBs have been shown to considerably degrade in water within one week at such temperatures [7]. Total water uptake and residual flexural properties are measured and analyzed for the exposed syntactic foams.

\section{MATERIALS AND METHODS}

\subsection{Constituent materials}

DER 332 epoxy resin (DOW Chemical Co., Midland, MI) cured with triethylene tetramine hardener (Huntsman Co., The Woodlands, TX) is used as the matrix resin. Three compositions of $\mathrm{CNF} /$ epoxy composites and fourteen compositions of CNF/syntactic foams are fabricated for this study. GMBs supplied by 3M (St. Paul, MN), of 220 and $460 \mathrm{~kg} / \mathrm{m}^{3}$ nominal true particle densities, are used in 15, 30 and 50 vol.\% in different types of syntactic foams. The various compositions fabricated for this study are illustrated in Figure 1. CNF/epoxy composites are fabricated with 1, 2, and 5 wt.\% CNFs, procured from Pyrograf Products, Inc., (Cedarville, OH). 
Vapor grown PR-24 XT-PS CNFs are used in the study (the nomenclature "XT" and "PS" denote that the CNFs have been debulked and have been pyrolytically stripped of aromatic hydrocarbons, respectively). In $\mathrm{CNF} /$ syntactic foams, the weight fraction of CNFs is calculated with respect to only the matrix system. The densities of CNFs and the epoxy resin are taken as 1950 and $1160 \mathrm{~kg} / \mathrm{m}^{3}$, respectively, from the manufacturers' datasheets. The composite nomenclature follows the trend where $\mathrm{N}$ represents $\mathrm{CNF}$ reinforcement, followed by $\mathrm{CNF}$ content, GMB density, and GMB volume fraction; for example, N1-460-15 represents a grade of CNF reinforced syntactic foam containing $1 \mathrm{wt} . \% \mathrm{CNF}$ and microballoons of $460 \mathrm{~kg} / \mathrm{m}^{3}$ density at a volume fraction of $15 \mathrm{vol} . \%$. The viscosity of the mixture during stirring increases at higher CNF content and makes it difficult to uniformly mix large amounts of GMBs without breaking them. Therefore, fewer compositions, having lower GMB content, are studied at high CNF content.

\subsection{Specimen fabrication method}

Specimen fabrication is conducted according to the previously optimized procedure described in [29]. A mechanical mixer with a high shear impeller is used to obtain uniform dispersion of CNFs in the epoxy resin [36]. GMBs and the hardener are then added and slowly mixed by hand using a wooden dowel for fifteen minutes so that the GMBs are uniformly dispersed and then cast in aluminum molds. This mixing method has previously been used to achieve satisfactory dispersion of CNF without clustering as well as uniform dispersion of GMB without breakage. The mixture is cured at room temperature for $24 \mathrm{~h}$ and post-cured in a convection oven for $2 \mathrm{~h}$ at $90^{\circ} \mathrm{C}$. 


\subsection{Flexural testing}

Flexural properties were measured using an Instron 4469 mechanical test system equipped with a $50 \mathrm{kN}$ load cell and Bluehill 2 software (Instron, Norwood, MA). Specimens had the nominal dimensions of $3 \times 11 \times 95 \mathrm{~mm}^{3}$. The flexural testing was conducted under a three-point bend configuration using cylindrical supports of $10 \mathrm{~mm}$ diameter and a specimen span length to thickness ratio of $16: 1$ as per the ASTM D790 standard. The crosshead velocity was set at 5 $\mathrm{mm} / \mathrm{min}$, where specimens were tested until fracture. Flexural stress and strain were calculated using [37]:

$$
\begin{gathered}
\sigma=\frac{3 P L}{2 b h^{2}} \\
\varepsilon=\frac{6 D d}{L^{2}}
\end{gathered}
$$

where $\sigma$ is flexural stress in the outer surface at the midpoint, $P$ is the load, $L$ is the span length, $b$ is the width of the beam, $d$ is the depth of the beam, $\varepsilon$ is strain in the outer surface at the midpoint, and $D$ is the mid-span deflection of the beam. At least five specimens of each type are tested for both the weathered and un-weathered condition.

\subsection{Moisture absorption testing}

The flexural test specimens were dried in a convection oven at $70^{\circ} \mathrm{C}$ for 2 hours to remove any surface moisture prior to the initial weighing and then immersed in deionized water maintained at $90^{\circ} \mathrm{C}$ for 14 days. Deionized water has been used previously in water uptake studies on plain syntactic foams that did not contain CNFs. Testing under similar conditions will allow direct comparison of the results obtained in the present study. The first weight measurement was taken 
after 10 minutes of immersion to determine the absorption in partially cut GMBs that are present on the specimen surface. The specimens were then weighed twice daily for the remainder of the immersion time. Five specimens of each type are subject to weathering.

\subsection{Microscopy}

Extensive microscopy of fracture surfaces and moisture exposed specimens was conducted using a Hitachi S3400N scanning electron microscope (SEM) (Hitachi USA, Schaumburg, IL). Prior to imaging, specimens were sputter coated with gold using an EM SCD050 sputter coater from Leica Microsystems (Buffalo Grove, IL).

\section{RESULTS}

\subsection{Moisture Absorption Behavior}

$\mathrm{CNF} /$ epoxy composites and $\mathrm{CNF} /$ syntactic foams are tested under identical conditions to understand the role of CNFs and GMBs in environmental degradation and residual flexural properties of the composites. Representative moisture uptake profiles are presented in Figure 2 for CNF/epoxy composites. The curve for the neat resin is also included in this figure. Only one curve for each material type is included in the figure for clarity. It can be observed that all nanocomposites have higher moisture uptake compared to neat resin. The moisture uptake saturates in 150-225 hours for the neat resin and CNF/epoxy composites. The maximum uptake is under $3.3 \mathrm{wt} . \%$ for all CNF/epoxy composites, which is about $18 \%$ higher than that for the neat resin. Inclusion of a second phase creates interfaces in the composite, which provide channels for moisture diffusion and increases water uptake [38-40]. 
Figure 3 shows the moisture uptake profile for $\mathrm{CNF} /$ syntactic foams. The highest average weight gain recorded for $\mathrm{CNF} /$ syntactic foams containing either 220 or 460 type GMBs are $8.3 \%$ for N1-220-50, and $10.0 \%$ for N1-460-50 for the immersion time of $336 \mathrm{~h}$. The maximum weight gain occurred in $\mathrm{CNF} /$ syntactic foams containing 50 vol.\% GMBs for both particle types. The profile indicates that complete saturation was not achieved in syntactic foams during the two week (336 h) immersion period at high temperature.

The elevated temperature moisture uptake profiles of CNF/epoxy and CNF/syntactic foams are compared with those of a previous study [7] conducted at room temperature in Figure 4. Similar trends can be deduced from both sets of data, where composites containing $220 \mathrm{~kg} / \mathrm{m}^{3}$ (thinner walled) GMBs at 50 vol.\% absorb higher amounts of moisture. However, for the room temperature (RT) testing, the range of maximum moisture uptake is between $0-4 \mathrm{wt} . \%$, whereas at higher temperatures (HT), the range is considerably higher at 3-10 wt.\%.

It has been previously established that the GMBs used in this composite are susceptible to significant degradation and even disintegration when subjected to high temperature moisture exposure [7]. In a separate experiment, GMBs were submersed in boiling water for one week. The degradation of these particles can be observed in Figure 5. The GMBs are composed of sodalime borosilicate glass. Ions of sodium can leach out of the glass into the water causing GMBs to degrade leading to the eventual failure of the particle wall at sufficiently long exposure time. 
It can be observed in SEM images presented in Figure 6 that the extent of GMB degradation within the composites varies throughout the thickness of $\mathrm{CNF} /$ syntactic foams, with the greatest degradation occurring near the surface, and minimal degradation apparent near the center of the specimens. Signs of degradation are observed in GMBs throughout the specimen cross section, verifying the diffusion of moisture throughout the specimen thickness. The composite shown in these images was found to increase in weight by $8.3 \%$ after two weeks of immersion, compared to the neat resin that plateaued at $2.8 \%$ weight gain in a shorter period of time.

Surface degradation of GMBs caused by moisture exposure tends to cause the outer layer of the GMB to flake or form fine particulates due to dealkalization [7], as seen in Figure 7a. Surface degradation could greatly increase the extent of GMB debonding as the bonded surface separates from the bulk of the GMB. Such a phenomenon can be observed in Figure $7 \mathrm{~b}$, which shows the remnants of a degraded and debonded GMB near the tensile surface of a wet N1-220-50 specimen. The modulus of dry syntactic foams varies with the GMB wall thickness [41]. This sensitivity to wall thickness disappears in the wet composites. CNFs are inert to water, so any changes in the mechanical properties of wet CNF/epoxy composites can be attributed to the changes in the matrix or the matrix-CNF interface. As identified by previous literature [42, 43], there may be at least two possible, competing moisture effects: (a) a debonding effect due to the attack of moisture at the interface and due to the degradation of particle surface by dealkalization and (b) a reinforcing effect, particularly increased traction on the CNFs due to swelling of the matrix and overall composite toughening due to increased ductility arising from plasticization. A resultant of these two effects determines the overall characteristics of the weathered composites. 


\subsection{Flexural Testing}

\subsubsection{CNF/epoxy composites}

As-fabricated (dry) composites and neat resin were also tested for flexural properties to obtain the baseline data for comparison with the results obtained on weathered (wet) specimens. Representative flexural stress-strain curves from CNF/epoxy composites tested under both wet and dry conditions are shown in Figure 8. The small stress plateau around $60 \mathrm{MPa}$ observed in some of the curves is an artifact of the test as slack in the loading head under compression. A comparison of the dry and wet flexural modulus and strength values of each composition is presented in Figure 9.

Figure 9a shows that the strength of neat resin, $106 \mathrm{MPa}$, is higher than CNF/epoxy composites. The strength of neat resin reduced drastically to $53 \mathrm{MPa}$ due to weathering. For the dry composites, N1 showed the highest fracture strength at 96.9 MPa. The N1 composite showed reduction in strength after weathering but the reduction is smaller compared to that for neat resin. The N2 and N5 composites have the higher strength after weathering. The N5 composite was observed to have improved strength after immersion, increasing by $27 \%$ with respect to the dry composite. The flexural modulus of dry specimens is nearly the same for neat resin and all compositions of CNF/epoxy composites. Figure $9 \mathrm{~b}$ shows that weathering has not affected the modulus significantly.

\subsubsection{CNF/syntactic foams}

The flexural strength and modulus of CNF/syntactic foams are compared in Figure 10 and Figure 11, respectively. Among the as-fabricated composites, N1-220-50 showed the lowest fracture 
strength at $32 \mathrm{MPa}, 69.4 \%$ lower than that of neat resin, and N2-460-15 showed the highest strength at $64 \mathrm{MPa}$. The flexural strength decreased and the flexural modulus increased with increasing CNF content. For compositions containing GMBs of $220 \mathrm{~kg} / \mathrm{m}^{3}$ density, the modulus decreased with increasing GMB content, while for compositions containing GMBs of $460 \mathrm{~kg} / \mathrm{m}^{3}$ density, the modulus increased with increasing GMB content.

Most composites and the neat resin showed decreases in strength after weathering, with the exceptions being CNF/syntactic foams containing 15 vol.\% GMBs and 5 wt.\% CNFs. These compositions showed $27-51 \%$ increase in strength compared to their respective dry strengths. The N5-460-15 composites and neat resin showed the maximum change in strength with respect to the respective dry specimens, with an increase of $51 \%$ and a decrease of $50 \%$ respectively. The flexural modulus of $\mathrm{CNF} /$ syntactic foams was observed to decrease. The maximum change in modulus was observed in N1-460-50, with a decrease of $61 \%$ with respect to the as-fabricated material. Unlike for the dry specimens, the modulus of weathered specimens was observed to decrease with increasing GMB content regardless of GMB wall thickness.

\section{DISCUSSION}

\subsection{Moisture Absorption Behavior}

Previous work has suggested a number of mechanisms for moisture uptake in syntactic foams [7]. Water may diffuse through the matrix resin, attack the particle-matrix interface, and degrade the particle. These mechanisms do not necessarily occur simultaneously and may have different progression rates and overlap with each other, especially at accelerated weathering conditions [7]. 
The diffusion occurring in the composite can be classified as Fickian [42], if the (a) moisture absorption graph shows an initially linear behavior with the square root of exposure time, (b) the glass transition temperature $\left(T_{g}\right)$ of material is higher than the test temperature, and (c) the overall water uptake is low. In addition to the initial linear portion of the moisture absorption graphs presented in Figure 2 and Figure 3, $T_{g}$ of these composites was measured in a previous study to be well over $100^{\circ} \mathrm{C}$ [28], and the overall water uptake in the present study for most composites is below 5 wt.\%. Therefore, to assess the diffusivity $D$ for the composites in this study, Fick's law was utilized as $[6,44,45]$ :

$$
D=\pi\left(\frac{h}{4 M\left(t_{4}\right)}\right)^{2}\left(\frac{M\left(t_{3}\right)-M\left(t_{2}\right)}{\sqrt{t_{3}}-\sqrt{t_{2}}}\right)^{2}
$$

where $M$ is the moisture content of the immersed specimen, defined as:

$$
M(t)=\frac{w(t)-w_{0}}{w_{0}}
$$

where $w(t)$ is the specimen weight as a function of immersion time and $w_{0}$ is the initial dry weight. The parameter $h$ is the specimen thickness, and times $t_{2}$ and $t_{3}$ are selected within the initial linear region of the moisture uptake graphs. $M\left(t_{4}\right)$ is the saturation concentration of moisture in the composite achieved at saturation time $t_{4}$. The CNF/epoxy composites show saturation, allowing for measurement of the saturation concentration and subsequently the diffusivity $D$ for various CNF loadings using Equation 4.

However, for the majority of $\mathrm{CNF} /$ syntactic foams in this study, a saturation concentration value is not reached within the testing duration, as shown in Figure 3. Therefore a semi-empirical estimation of $M\left(t_{4}\right)$ is developed through predicting saturation weight gain. The estimation is 
obtained using the proposed moisture uptake mechanisms of these composites in order to predict saturation weight gain [7]. The initial density is given by Equation 1 and the density of the moisture impregnated specimens $\left(\rho_{c}^{S}\right)$ is represented as

$$
\rho_{c}^{S}=\left(1+M_{m}\right) \rho_{m} \phi_{m}+\left(\rho_{g}\left(1-\eta^{3}\right)+\rho_{w} \eta^{3}\right) \phi_{b}
$$

The terms $M_{m}, \rho_{g}$, and $\rho_{w}$ represent the $\mathrm{CNF} /$ epoxy matrix saturation moisture uptake, the GMB glass density, and the moisture density that penetrates them, respectively. The radius ratio $\eta$ is defined as the ratio of internal to the outer radius of GMBs and is related to the wall thickness [46-48]. For the estimation shown in Equation 6, the following assumptions about the nature of the saturated composite are noted: (a) GMBs are penetrated by moisture, and the void of the GMBs is filled with water, (b) no material leaves the composite, and (c) volumetric expansion of the composite is neglected, allowing the moisture concentration to be found as the relative gain in density. Validation of estimates obtained from Equation 6 was performed by comparing the theoretical values for plain epoxy matrix syntactic foams reported in the literature to be fully saturated after long-term moisture immersion. Comparing the theoretical predictions obtained from Equation 6 with the experimental values reported in [5] and [14] for one syntactic foam each by another group yields an error of $2.5 \%$ and $5.9 \%$ respectively. Such small differences with the third-party data establish the validity of the approach.

Table 1 and Table 2 list the diffusivity values obtained for the CNF/epoxy and CNF/syntactic foam composites, respectively. The standard deviations are large in the values obtained for CNF/epoxy composites and show a general trend of increasing diffusivity with CNF content, which indicates a role of CNF-epoxy interface in providing a diffusion path to the moisture. The moisture diffusivity in $\mathrm{CNF} /$ syntactic foams is observed to decrease by one to two orders of 
magnitude with increases in GMB content. This trend, along with the magnitude of diffusivity $\left(\sim 10^{-9} \mathrm{~cm}^{2} / \mathrm{s}\right)$ coincides with previous moisture absorption studies on plain syntactic foam [6]. This trend is likely due to reduced amount of epoxy in the composite as the GMB content is increased. The standard deviations in the diffusivity values are significantly high because of possible effects related to GMB distribution on the surface and sub-surface regions.

As shown in Figure 4, where the present results are compared with those from a previous study conducted at room temperature [7], the rate and extent of moisture uptake in composites is sensitive to temperature. Most compositions in the room-temperature study were observed to plateau at $0.75-2 \%$ weight gain, while N1-220-50 showed a 7\% weight gain without plateauing. Such trend was attributed to the degradation of thin walled particles to the extent that the moisture started accumulating in the cavity inside the particle. Accelerated degradation in the present study is likely due to a similar mechanism, which results in the observation that the composite is not saturated within the test time frame. Such possibility will be further examined through microscopy.

\subsection{Flexural Properties}

A differential scheme has previously been applied to syntactic foams containing high volume fraction of particles to predict the elastic properties. This model defines the variation in the elastic modulus $d E$ due to incremental addition of GMB volume fraction $d \Phi$ by [47]:

$$
d E=f_{E}\left(E_{p}, v_{p}, E, \nu, \eta\right) E d \Phi
$$

where $E_{p}$ and $v_{p}$ represent the elastic modulus and the Poisson's ratio of GMB material, and $E$ and $v$ represent the composite elastic modulus and Poisson's ratio. In the calculation, $E_{p}$ and $v_{p}$ 
are taken as $60 \mathrm{GPa}$ and 0.21 , respectively and the Poisson's ratio of all composites is taken as 0.35. The full expression for the model is lengthy and has no closed form solution; the reader is directed to the original article [47]. Since this model is only applicable to plain syntactic foams, the experimentally measured modulus of various grades of $\mathrm{CNF} / \mathrm{epoxy}$ are assigned to be the matrix modulus of corresponding grades of $\mathrm{CNF} /$ syntactic foams [27]. For example, to predict the modulus of N5-220-15, the modulus of the N5 composite would be used as the matrix modulus.

The flexural modulus values for CNF/syntactic foams having 220 and $460 \mathrm{~kg} / \mathrm{m}^{3}$ density GMBs can be observed in Figure 12 and Figure 13, respectively. It can be seen that there is closer agreement among the modulus values of dry specimens compared to those of wet specimens. The average difference between the experimental and theoretical values for the dry composites is $9.4 \%$ with a maximum of $29 \%$ for the N2-220-15 composite. The average deviation for the wet composites is $32.4 \%$ with a maximum of $62 \%$ for the $\mathrm{N} 1-460-50$ composite. It is also observed that the difference between experimental and theoretical values increases with GMB volume fraction. These observations establish the role of particle degradation in the overall degradation of $\mathrm{CNF} /$ syntactic foams because the model does not account for degradation of the hollow particles or changes to the particle-matrix interface and the predictions represent the values based only on the matrix degradation.

\subsection{Microscopy}

The fracture surface of a wet N5 composite is shown in Figure 14a. The evidence of fiber-matrix debonding and fiber pull-out can be observed in this figure in the form of several holes and 
pulled out fibers. This is in contrast to failure features for the dry N5 composite shown in Figure $14 \mathrm{~b}$, where there appears to be no indications of fiber debonding or fiber pullout. The fibers are elongated and fractured in this figure, similar to the features observed in previous studies on tensile surface of CNF/epoxy composites [30]. The debonding effect in N1 composites results in a decrease of flexural strength of wet composites, shown in Figure 9. However, as the CNF content increases, the difference between the flexural strength of wet and dry composites reduces, such that the wet N5 composites show a higher strength than the dry N5 composites. Therefore, addition of sufficiently high content of CNFs can help in retaining the strength in composites after environmental exposure. Similar effects are also noted in the syntactic foam composites containing 2 and $5 \mathrm{wt} . \% \mathrm{CNFs}$.

Given that the strength of neat resin has decreased due to moisture exposure, as shown in Figure 9, it can be proposed that the reinforcing effect of CNFs is likely due to increased traction due to the swelling of epoxy. It has been shown that cured epoxy resins will swell by approximately the volume of water absorbed when exposed to moisture [49]. A single debonded fractured CNF is shown in Figure 15, where turbostratic carbon layers have broken and slid over graphitic layers. The fiber also shows cup and cone fracture that represents the stacked cup structure of the vapor grown $\mathrm{CNFs}$, as observed in previous $\mathrm{CNF}$ fracture studies [50]. In comparing the elongated, deformed fiber with the morphology of the surface indent of the original fiber position, it can be proposed that the fiber carried load even after fracture of the matrix, thus assisting in strength retention under weathered conditions. 


\section{CONCLUSIONS}

In the present work, $\mathrm{CNF} /$ epoxy composites and $\mathrm{CNF} /$ syntactic foams were subjected to accelerated weathering and studied for their residual flexural properties. Specimens immersed in $90^{\circ} \mathrm{C}$ water for two weeks were subjected to three-point bending flexural tests. The following conclusions were obtained:

- The extent of moisture uptake was observed to be dependent on GMB volume fraction, with greater moisture uptake seen in composites with greater GMB volume fraction, and largely independent of CNF content.

- After weathering, all CNF/epoxy composites were observed to have greater strength than the moisture exposed neat resin. The N5 composite was observed to increase in strength by $27 \%$ with respect to the as-fabricated material. Overall, changes in strength from $38 \%$ decrease to $51 \%$ increase were observed for the composites tested, and changes in modulus from $61 \%$ decrease to insignificant change were observed.

- A differential scheme demonstrates the significance of accounting for GMB degradation due to discrepancies between model predictions and experimental values of wet $\mathrm{CNF} /$ syntactic foam composites.

- Strengthening and retention of mechanical properties of the composites after weathering was determined to be the result of increased traction on the nanofibers due to swelling of the matrix and changes in matrix surface morphology.

\section{ACKNOWLEDGMENTS}

This work is supported by the Office of Naval Research through the grant N00014-07-1-0419 and the National Science Foundation GK-12 Fellows grant 0741714. The authors thank 3M, MN 
for providing microballoons and relevant technical information. Matthew Labella and Sandy Shen are thanked for assistance in specimen preparation and testing. The undergraduate summer research program at NYU-Poly is thanked for funding the undergraduate students.

The views and conclusions contained in this paper are those of the authors and should not be interpreted as presenting the official policies or position, either expressed or implied, of the ONR or the U.S. Government unless so designated by other authorized documents.

\section{REFERENCES}

1. Gupta, N., Zeltmann, S.E., Shunmugasamy, V.C., and Pinisetty, D., Applications of polymer matrix syntactic foams. JOM, 2014. 66(2): p. 245-254.

2. Sauvant-Moynot, V., Gimenez, N., and Sautereau, H., Hydrolytic ageing of syntactic foams for thermal insulation in deep water: degradation mechanisms and water uptake model. Journal of Materials Science, 2006. 41(13): p. 4047-4054.

3. Gupta, N., Pinisetty, D., and Shunmugasamy, V.C., Reinforced polymer matrix syntactic foams: effect of nano and micro-scale reinforcement. 2013, New York: Springer.

4. Grosjean, F., Bouchonneau, N., Choqueuse, D., and Sauvant-Moynot, V., Comprehensive analyses of syntactic foam behaviour in deepwater environment. Journal of Materials Science, 2009. 44(6): p. 1462-1468.

5. Sauvant-Moynot, V., Duval, S., Gimenez, N., and Kittel, J., Hot wet aging of glass syntactic foam coatings monitored by impedance spectroscopy. Progress in Organic Coatings, 2007. 59(3): p. 179-185.

6. Tagliavia, G., Porfiri, M., and Gupta, N., Influence of moisture absorption on flexural properties of syntactic foams. Composites Part B: Engineering, 2012. 43(2): p. 115-123. 
7. Poveda, R.L., Dorogokupets, G., and Gupta, N., Carbon nanofiber reinforced syntactic foams: Degradation mechanism for long term moisture exposure and residual compressive properties. Polymer Degradation and Stability, 2013. 98(10): p. 2041-2053.

8. Gimenez, N., Sauvant-Moynot, V., and Satureau, H. Wet ageing of syntactic foams under high pressure/high temperature in deionized water. in International Conference on Offshore Mechanics and Arctic Engineering. 2006. June 12-17, Halkidiki, Greece. Vol. 3, pp. 205-210.

9. Lefebvre, X., V. Sauvant-Moynot, D. Choqueuse, and P. Chauchot, Durability of syntactic foams for deep offshore insulation: modelling of water uptake under representative ageing conditions in order to predict the evolution of buoyancy and thermal conductivity. Oil \& Gas Science and Technology, 2009. 64(2): p. 165-178.

10. Ishai, O., Hiel, C., and Luft, M., Long-term hygrothermal effects on damage tolerance of hybrid composite sandwich panels. Composites, 1995. 26(1): p. 47-55.

11. Karthikeyan, C.S. and Sankaran, S., Effect of Absorption in Aqueous and Hygrothermal Media on the Compressive Properties of Glass Fiber Reinforced Syntactic Foam. Journal of Reinforced Plastics and Composites, 2001. 20(11): p. 982-993.

12. Gupta, N. and Woldesenbet, E., Hygrothermal studies on syntactic foams and compressive strength determination. Composite Structures, 2003. 61(4): p. 311-320.

13. Sadler, R.L., Sharpe, M., Panduranga, R., and Shivakumar, K., Water immersion effect on swelling and compression properties of Eco-Core, PVC foam and balsa wood. Composite Structures, 2009. 90(3): p. 330-336. 
14. Grosjean, F. and Sauvant-Moynot, V., Acoustic emission analyses of the hygrothermal ageing of glass syntactic foams. Science and Engineering of Composite Materials, 2011. 18(4): p. 217-223.

15. $\mathrm{Xu}, \mathrm{T}$. and Li, G., Durability of shape memory polymer based syntactic foam under accelerated hydrolytic ageing. Materials Science and Engineering: A, 2011. 528(24): p. 7444-7450.

16. Capela, C., Costa, J.D., and Ferreira, J.A.M., Test Conditions Effect on the Fracture Toughness of Hollow Glass Micro-sphere Filled Composites. Strain, 2008. 44(2): p. 141146.

17. Strauchs, A., Mashkin, A., Schnettler, A., and Podlazly, J. The impact of water absorption on the dielectric properties of syntactic foam. in 2010 10th IEEE International Conference on Solid Dielectrics (ICSD). 2010.

18. Roggendorf, C. and Schnettler, A., Accelerated hydrothermal aging of epoxy resin based syntactic foams with polymeric microspheres. IEEE Transactions on Dielectrics and Electrical Insulation, 2012. 19(3): p. 973-980.

19. Andritsch, T., Lunding, A., Morshuis, P.H.F., Negle, H., and Smit, J.J. The Investigation of the Permittivity of Syntactic Foam under varying Humidity. in Electrical Insulation and Dielectric Phenomena, 2008. CEIDP 2008. Annual Report Conference on. 2008.

20. Wouterson, E.M., Boey, F.Y.C., Hu, X., and Wong, S.-C., Effect of fiber reinforcement on the tensile, fracture and thermal properties of syntactic foam. Polymer, 2007. 48(11): p. 3183-3191. 
21. Gupta, N., Woldesenbet, E., and Kishore, Compressive fracture features of syntactic foams-microscopic examination. Journal of Materials Science, 2002. 37(15): p. 31993209.

22. Bardella, L., Malanca, F., Ponzo, P., Panteghini, A., and Porfiri, M., A micromechanical model for quasi-brittle compressive failure of glass-microballoons/thermoset-matrix syntactic foams. Journal of the European Ceramic Society, 2014. 34(11): p. 2605-2616.

23. Zhu, J., Wei, S., Ryu, J., Budhathoki, M., Liang, G., and Guo, Z., In situ stabilized carbon nanofiber (CNF) reinforced epoxy nanocomposites. Journal of Materials Chemistry, 2010. 20: p. 4937-4948.

24. Gu, H., Guo, J., Wei, H., Yan, X., Ding, D., Zhang, X., He, Q., Tadakamalla, S., Wang, X., Ho, T.C., Wei, S., and Guo, Z., Transparent anhydride-cured epoxy nanocomposites reinforced with polyaniline stabilized nanosilica. Journal of Materials Chemistry C, 2015. 3: p. 8152-8165.

25. Zhang, X., Alloul, O., He, Q., Zhu, J., Verde, M.J., Li, Y., Wei, S., and Guo, Z., Strengthened magnetic epoxy nanocomposites with protruding nanoparticles on the graphene nanosheets. Polymer, 2013. 54(14): p. 3594-3604.

26. Zhang, L. and Ma, J., Effect of carbon nanofiber reinforcement on mechanical properties of syntactic foam. Materials Science and Engineering: A, 2013. 574(1): p. 191-196.

27. Poveda, R., Achar, S., and Gupta, N., Thermal Expansion of Carbon NanofiberReinforced Multiscale Polymer Composites. JOM, 2012. 64(10): p. 1148-1157.

28. Poveda, R.L., Achar, S., and Gupta, N., Viscoelastic properties of carbon nanofiber reinforced multiscale syntactic foam. Composites Part B: Engineering, 2014. 58(1): p. 208-216. 
29. Dimchev, M., Caeti, R., and Gupta, N., Effect of carbon nanofibers on tensile and compressive characteristics of hollow particle filled composites. Materials \& Design, 2010. 31(3): p. 1332-1337.

30. Poveda, R.L. and Gupta, N., Carbon-nanofiber-reinforced syntactic foams: compressive properties and strain rate sensitivity. JOM: Journal of Minerals, Metals, and Materials Society, 2013. 66(1): p. 66-77.

31. Poveda, R.L. and Gupta, N., Carbon Nanofiber Reinforced Polymer Composites. Springer Brief in Materials. 2015: Springer, NY.

32. Gutiérrez, O. and Palza, H., Effect of carbon nanotubes on thermal pyrolysis of high density polyethylene and polypropylene. Polymer Degradation and Stability, 2015. 120: p. $122-134$.

33. Pandey, J.K., Raghunatha Reddy, K., Pratheep Kumar, A., and Singh, R.P., An overview on the degradability of polymer nanocomposites. Polymer Degradation and Stability, 2005. 88(2): p. 234-250.

34. Starkova, O., Chandrasekaran, S., Prado, L.A.S.A., Tölle, F., Mülhaupt, R., and Schulte, K., Hydrothermally resistant thermally reduced graphene oxide and multi-wall carbon nanotube based epoxy nanocomposites. Polymer Degradation and Stability, 2013. 98(2): p. 519-526.

35. Wu, D., Wu, L., Zhang, M., and Zhao, Y., Viscoelasticity and thermal stability of polylactide composites with various functionalized carbon nanotubes. Polymer Degradation and Stability, 2008. 93(8): p. 1577-1584. 
36. Colloca, M., Gupta, N., and Porfiri, M., Tensile properties of carbon nanofiber reinforced multiscale syntactic foams. Composites Part B: Engineering, 2013. 44(1): p. 584-591.

37. ASTM International, ASTM Standard D7264, "Standard Test Method for Flexural Properties of Polymer Matrix Composite Materials". 2007: West Conshohocken, PA.

38. Najafi, S.K., Kiaefar, A., Hamidina, E., and Tajvidi, M., Water Absorption Behavior of Composites from Sawdust and Recycled Plastics. Journal of Reinforced Plastics and Composites, 2007. 26(3): p. 341-348.

39. Hodzic, A., Kim, J.K., Lowe, A.E., and Stachurski, Z.H., The effects of water aging on the interphase region and interlaminar fracture toughness in polymer-glass composites. Composites Science and Technology, 2004. 64(13-14): p. 2185-2195.

40. Tsenoglou, C.J., Pavlidou, S., and Papaspyrides, C.D., Evaluation of interfacial relaxation due to water absorption in fiber-polymer composites. Composites Science and Technology, 2006. 66(15): p. 2855-2864.

41. Gupta, N., Ye, R., and Porfiri, M., Comparison of tensile and compressive characteristics of vinyl ester/glass microballoon syntactic foams. Composites Part B: Engineering, 2010. 41(3): p. 236-245.

42. Abot, J.L., Yasmin, A., and Daniel, I.M., Hygroscopic Behavior of Woven Fabric Carbon-Epoxy Composites. Journal of Reinforced Plastics and Composites, 2005. 24(2): p. $195-207$.

43. Weitsman, Y.J., Fluid Effects in Polymers and Polymeric Composites. Mechanical Engineering Series. Vol. 15. 2012, Knoxville, TN: Springer. 
44. Shen, C.-H. and Springer, G.S., Moisture Absorption and Desorption of Composite Materials. Journal of Composite Materials, 1976. 10(1): p. 2-20.

45. Srihari, S., Revathi, A., and Rao, R.M.V.G.K., Hygrothermal Effects on RT-Cured GlassEpoxy Composites in Immersion Environments. Part A: Moisture Absorption Characteristics. Journal of Reinforced Plastics and Composites, 2002. 21(11): p. 983991.

46. Gupta, N., Woldesenbet, E., and Mensah, P., Compression properties of syntactic foams: effect of cenosphere radius ratio and specimen aspect ratio. Composites Part A: Applied Science and Manufacturing, 2004. 35(1): p. 103-111.

47. Porfiri, M. and Gupta, N., Effect of volume fraction and wall thickness on the elastic properties of hollow particle filled composites. Composites Part B: Engineering, 2009. 40(2): p. 166-173.

48. Poveda, R., Gupta, N., and Porfiri, M., Poisson's ratio of hollow particle filled composites. Materials Letters, 2010. 64(21): p. 2360-2362.

49. Adamson, M.J., Thermal expansion and swelling of cured epoxy resin used in graphitelepoxy composite materials Journal of Materials Science, 1980. 15: p. 17361745.

50. Ozkan, T., Naraghi, M., and Chasiotis, I., Mechanical properties of vapor grown carbon nanofibers. Carbon, 2010. 48(1): p. 239-244. 


\section{FIGURE CAPTIONS}

Figure 1. Compositions of CNF/epoxy composites and CNF/syntactic foams studied. The black lines represent the CNF while the blue open circles represent the GMB.

Figure 2. Moisture uptake profiles for a representative specimen of each type of CNF/epoxy composites. The curve for a specimen of neat epoxy resin is also included.

Figure 3. Representative moisture uptake profiles for selected grades of $\mathrm{CNF} /$ syntactic foams containing (a) 220 and (b) $460 \mathrm{~kg} / \mathrm{m}^{3}$ density particles.

Figure 4. Comparison of moisture uptake observed in present study with moisture uptake at room temp from [7]. The dashed lines represent data from the present study at higher temperatures (HT), while the solid lines represent data from the previous study performed at room temperature (RT).

Figure 5. (a)-(b) As-received glass hollow microballoons before moisture exposure at two different magnificaitons. Degradation of 460-type GMBs immersed in boiling deionized water for 7 days: (c) micron and sub-micron size particle formation and (d) flaking of surface are characteristic of dealkalization of GMBs due to moisture exposure.

Figure 6. Moisture degradation of GMBs in N1-220-50 composite. Images are taken at (a) 55 $\mu \mathrm{m}$, (b) $300 \mu \mathrm{m}$, (c) $750 \mu \mathrm{m}$, and (d) $1250 \mu \mathrm{m}$ depth from specimen surface.

Figure 7. (a) Surface degradation and debonding of GMBs and (b) GMB degradation leading to separation of GMB from the matrix near tensile surface of wet N1-220-50 flexural test specimen. The particulate residue from GMB degradation remains bonded to the matrix in (b).

Figure 8. Representative flexural stress-strain curves of select CNF/epoxy composites and neat epoxy resin under (a) dry and (b) wet conditions.

Figure 9. Comparison of dry and wet (a) flexural strength and (b) flexural modulus of $\mathrm{CNF} /$ epoxy composites.

Figure 10. Comparison of dry and wet flexural strength of $\mathrm{CNF} /$ syntactic foams containing GMBs of (a) $220 \mathrm{~kg} / \mathrm{m}^{3}$ and (b) $460 \mathrm{~kg} / \mathrm{m}^{3}$ density.

Figure 11. Comparison of dry and wet flexural modulus of (a) $220 \mathrm{~kg} / \mathrm{m}^{3}$ and (b) $460 \mathrm{~kg} / \mathrm{m}^{3}$ GMB CNF/syntactic foams.

Figure 12. Comparison of experimental and theoretical flexural modulus of (a) dry and (b) wet CNF/syntactic foams containing $220 \mathrm{~kg} / \mathrm{m}^{3}$ GMBs.

Figure 13. Comparison of experimental and theoretical flexural modulus of (a) dry and (b) wet $\mathrm{CNF} /$ syntactic foams containing $460 \mathrm{~kg} / \mathrm{m}^{3}$ GMBs.

Figure 14. Comparison of fracture surfaces of (a) wet and (b) dry N5 CNF/epoxy composite. The wet specimens show debonding and fiber pull out.

Figure 15. (a) Debonding of CNFs on fracture surface of N5 CNF/epoxy composite. Region corresponding to box F and $\mathrm{E}$ are elaborated in (b) and (c), respectively. (b) Cup and cone type fracture of $\mathrm{CNF}$ and (c) fracture of turbostratic carbon layers and sliding over internal graphitic layers. 


\section{Tables}

Table 1: Diffusivity values for CNF/epoxy composites.

\begin{tabular}{ccc}
\hline Material Type & $\begin{array}{c}\text { Average Diffusivity } \\
\left(\mathbf{c m}^{\mathbf{2}} / \mathbf{s} \times \mathbf{1 0}^{-\mathbf{9}}\right)\end{array}$ & $\begin{array}{c}\text { Standard Deviation } \\
\left(\times \mathbf{1 0}^{-\mathbf{9}}\right)\end{array}$ \\
\hline Resin & 88.65 & 17.49 \\
N1 & 77.58 & 24.13 \\
N2 & 102.61 & 11.09 \\
N5 & 94.02 & 32.37 \\
\hline
\end{tabular}

Table 2: Diffusivity values for CNF/syntactic foam composites.

\begin{tabular}{ccc}
\hline Composite Type & $\begin{array}{c}\text { Average Diffusivity } \\
\left(\mathbf{c m}^{\mathbf{2}} / \mathbf{s} \times \mathbf{1 0}^{-9}\right)\end{array}$ & $\begin{array}{c}\text { Standard Deviation } \\
\left(\times \mathbf{1 0}^{-9}\right)\end{array}$ \\
\hline N1-220-15 & 6.30 & 1.77 \\
N2-220-15 & 1.11 & 0.30 \\
N5-220-15 & 3.89 & 1.33 \\
N1-220-30 & 0.25 & 0.08 \\
N2-220-30 & 0.20 & 0.09 \\
N5-220-30 & 0.57 & 0.13 \\
N1-220-50 & 0.21 & 0.04 \\
N1-460-15 & 8.48 & 2.40 \\
N2-460-15 & 3.92 & 1.09 \\
N5-460-15 & 3.28 & 1.15 \\
N1-460-30 & 0.36 & 0.12 \\
N2-460-30 & 0.73 & 0.14 \\
N5-460-30 & 1.28 & 0.56 \\
N1-460-50 & 0.33 & 0.08 \\
\hline
\end{tabular}




\section{Figures}

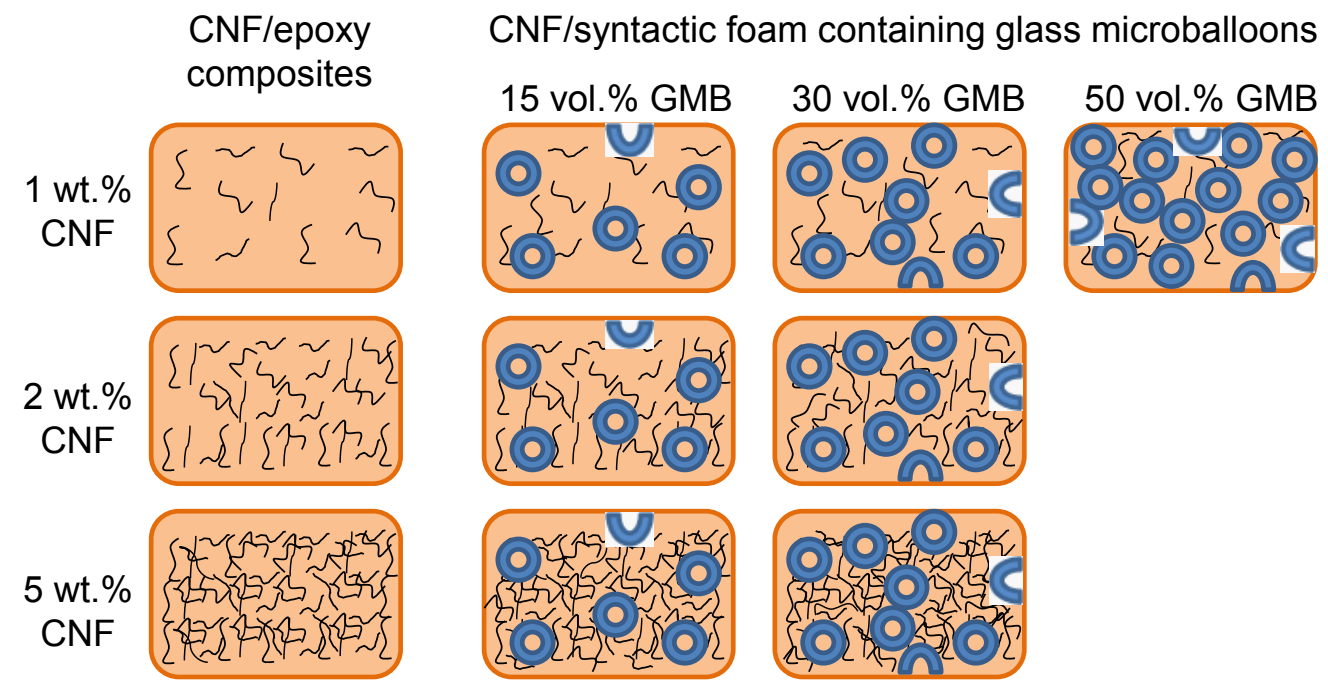

Figure 1. Compositions of CNF/epoxy composites and CNF/syntactic foams studied. The black lines represent the CNF while the blue open circles represent the GMB. 


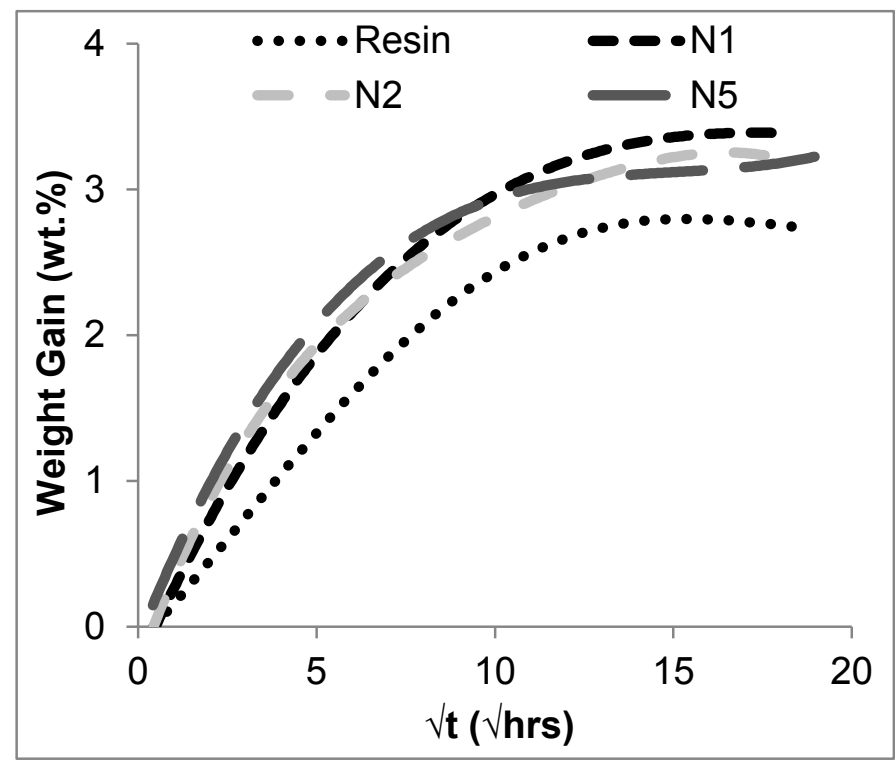

Figure 2. Moisture uptake profiles for a representative specimen of each type of CNF/epoxy composites. The curve for a specimen of neat epoxy resin is also included. 


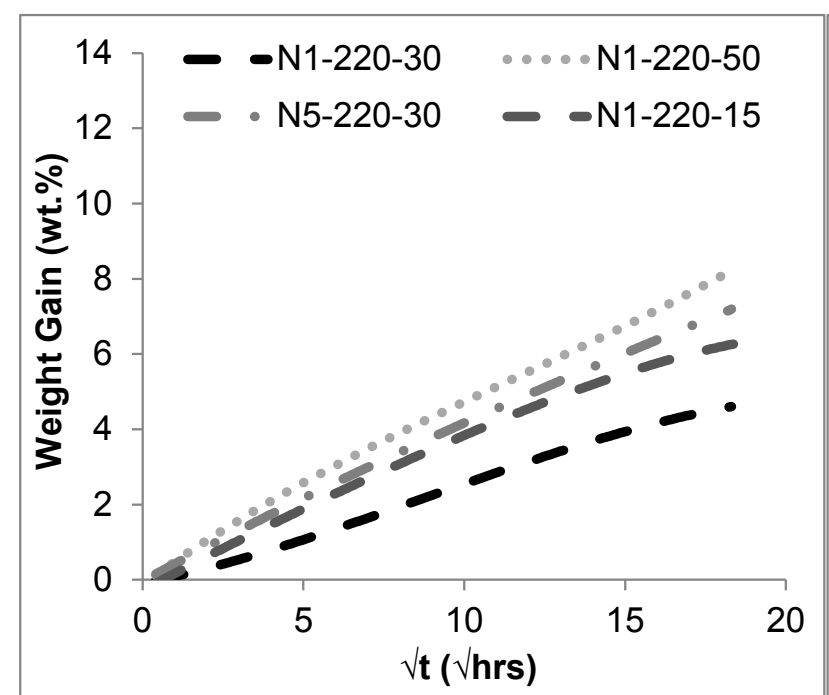

(a)

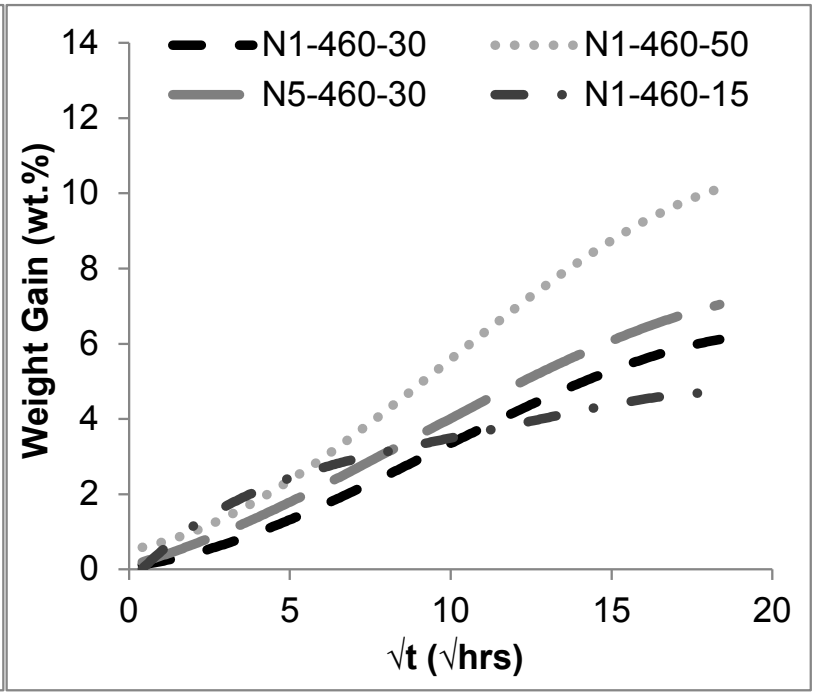

(b)

Figure 3. Representative moisture uptake profiles for selected grades of CNF/syntactic foams containing (a) 220 and (b) $460 \mathrm{~kg} / \mathrm{m}^{3}$ density particles.

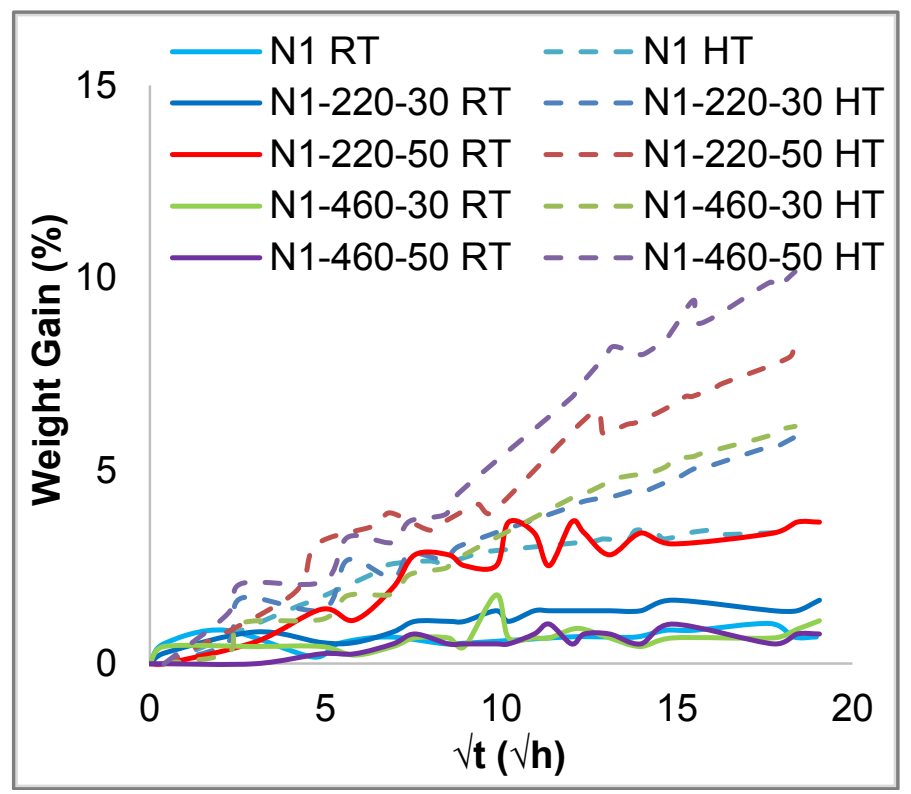

Figure 4. Comparison of moisture uptake observed in present study with moisture uptake at room temp from [7]. The dashed lines represent data from the present study at higher temperatures (HT), while the solid lines represent data from the previous study performed at room temperature (RT). 


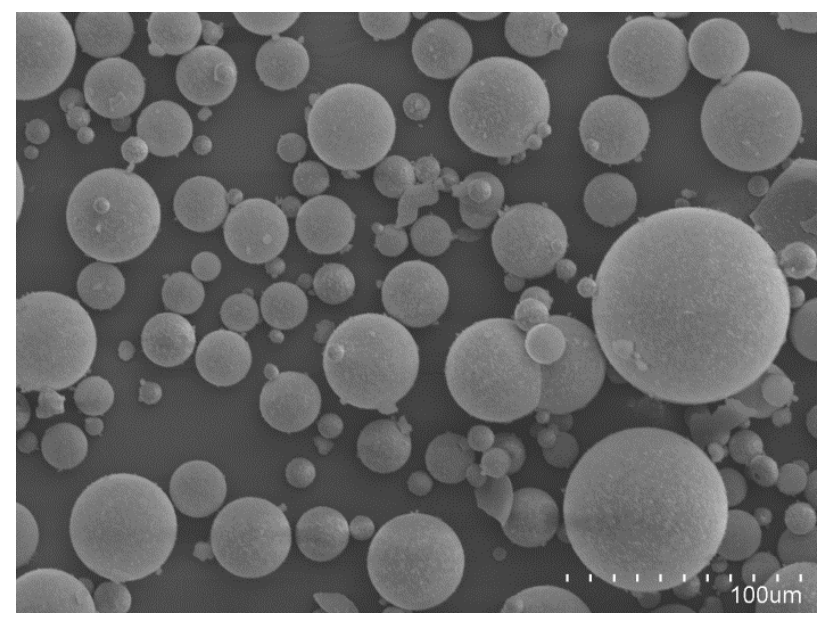

(a)

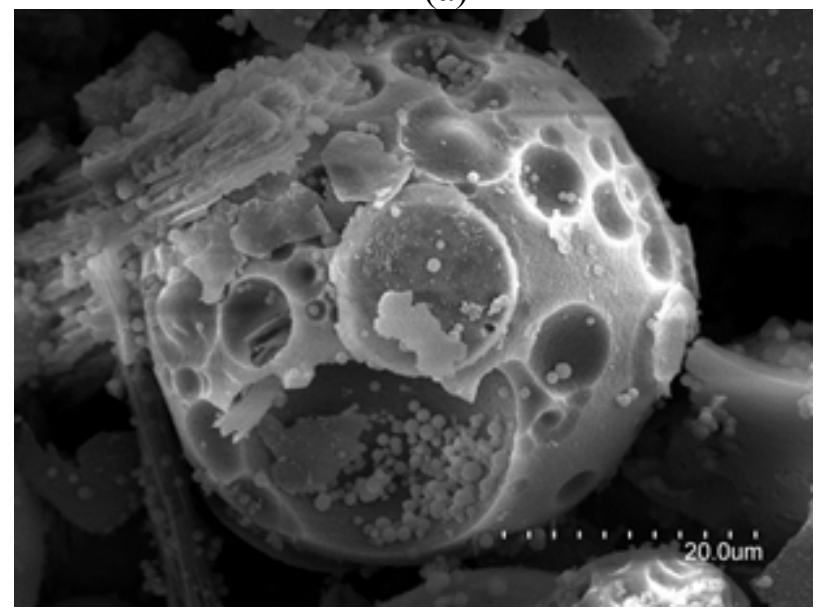

(c)

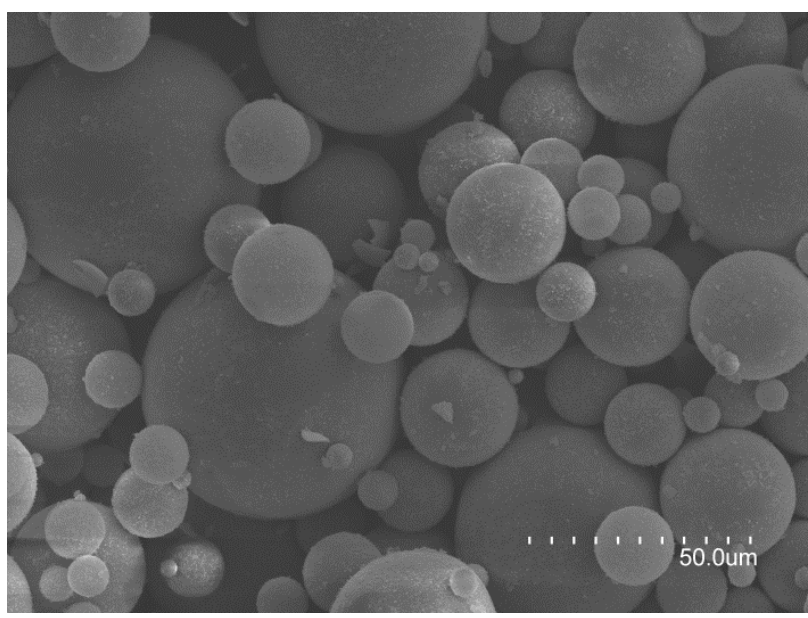

(b)

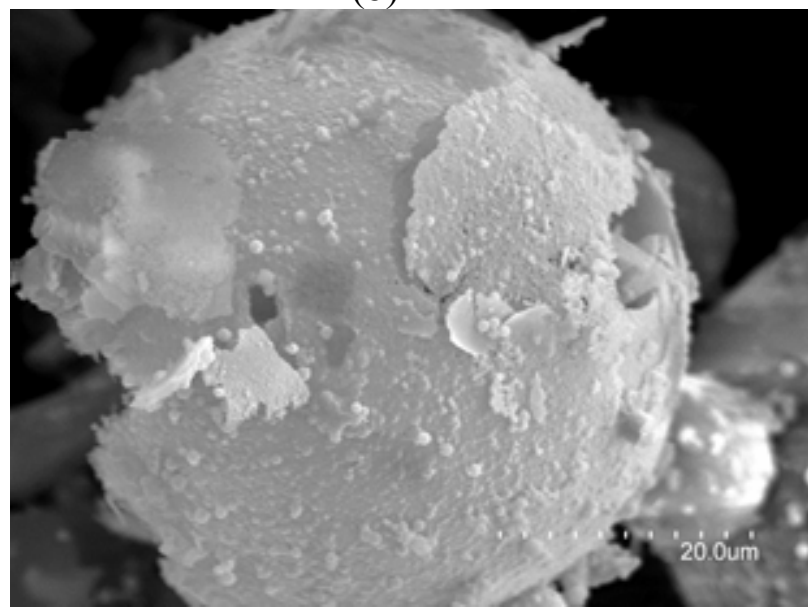

(d)

Figure 5. (a)-(b) As-received glass hollow microballoons before moisture exposure at two different magnificaitons. Degradation of 460-type GMBs immersed in boiling deionized water for 7 days: (c) micron and sub-micron size particle formation and (d) flaking of surface are characteristic of dealkalization of GMBs due to moisture exposure. 


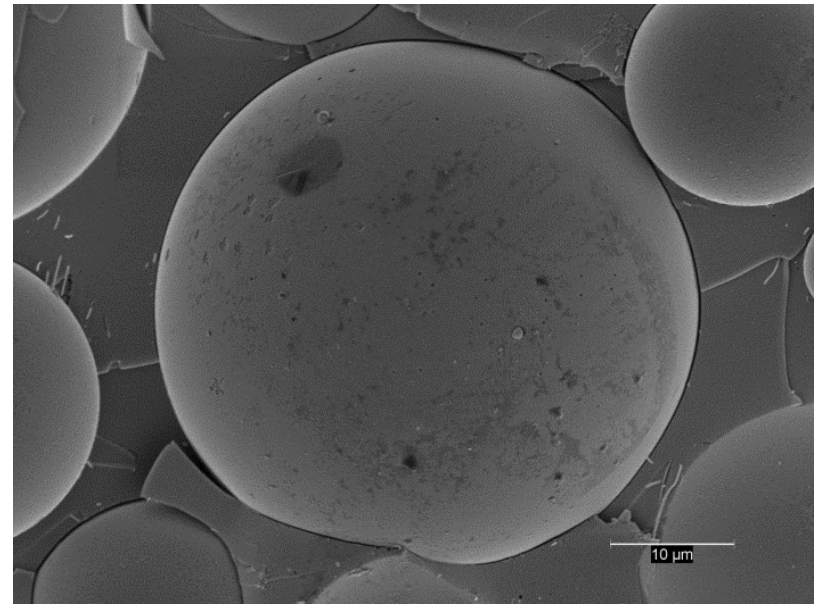

(a)

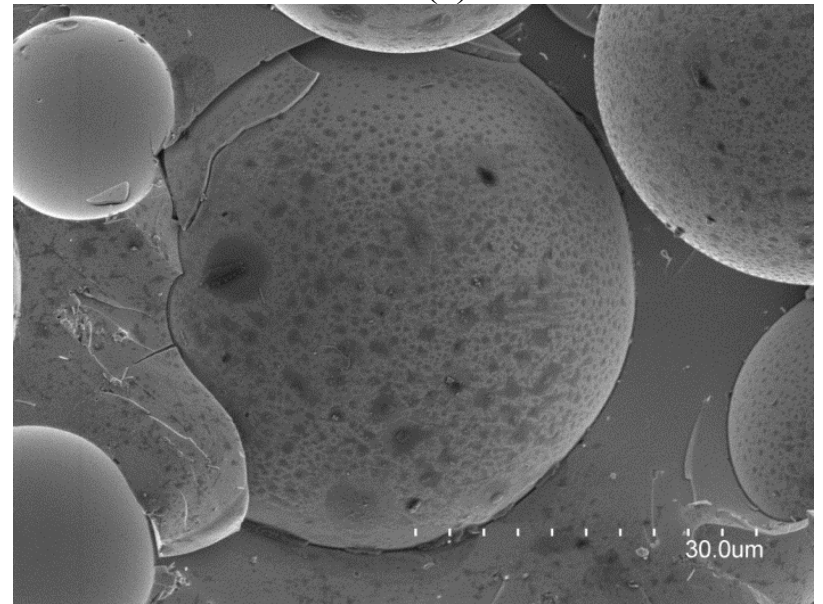

(c)

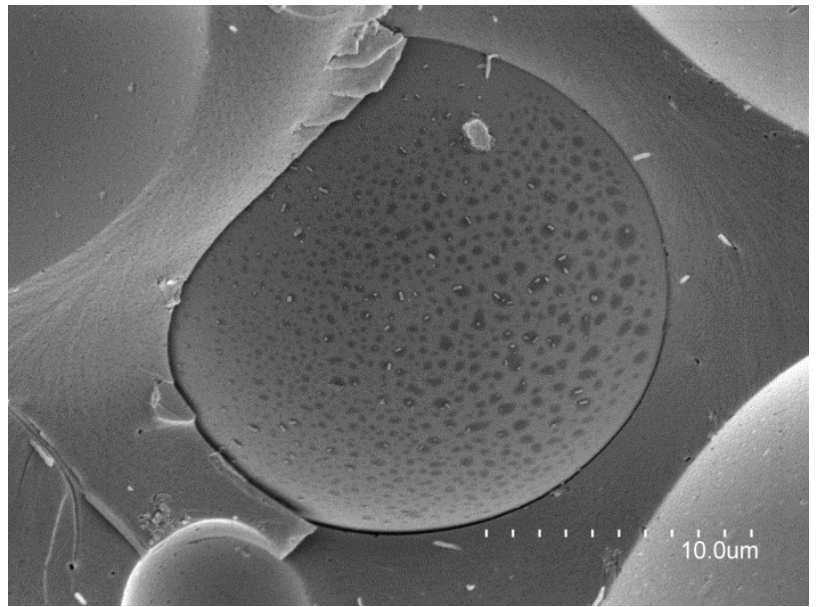

(b)

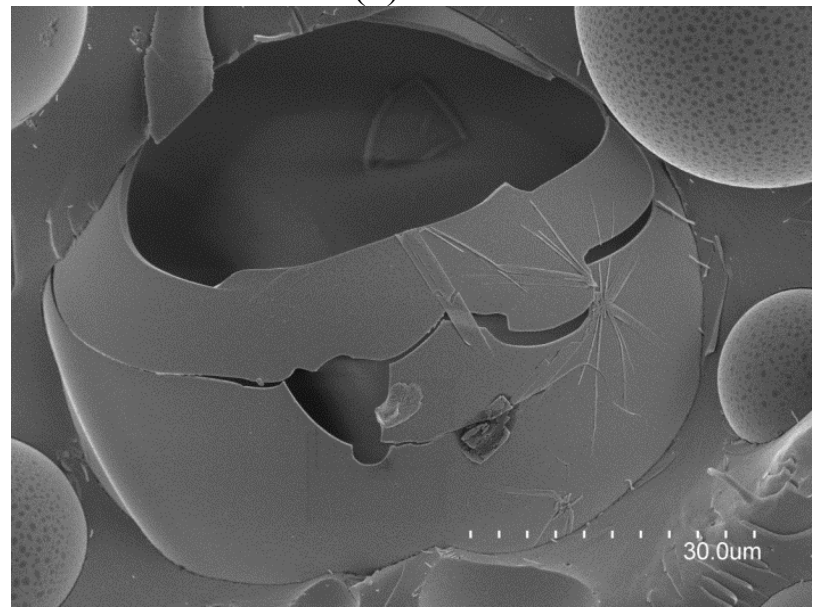

(d)

Figure 6. Moisture degradation of GMBs in N1-220-50 composite. Images are taken at (a) $55 \mu \mathrm{m}$, (b) $300 \mu \mathrm{m}$, (c) $750 \mu \mathrm{m}$, and (d) $1250 \mu \mathrm{m}$ depth from specimen surface. 

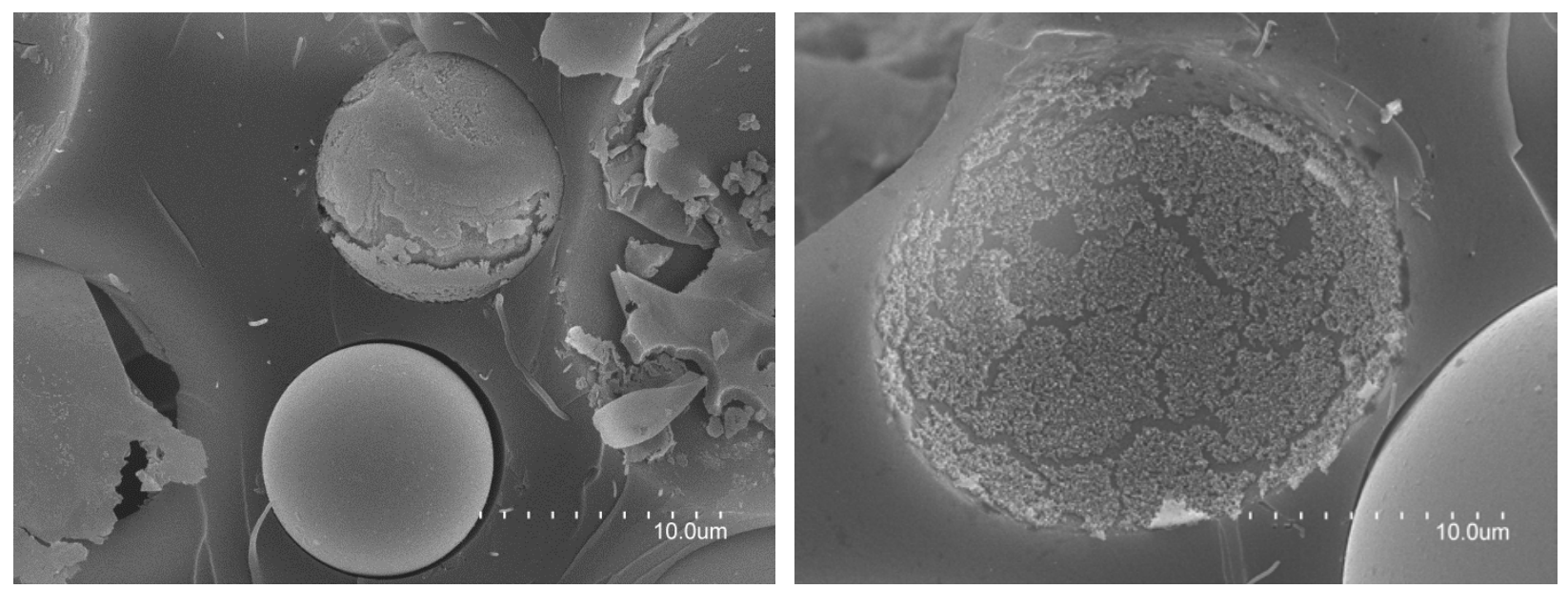

Figure 7. (a) Surface degradation and debonding of GMBs and (b) GMB degradation leading to separation of GMB from the matrix near tensile surface of wet N1-220-50 flexural test specimen. The particulate residue from GMB degradation remains bonded to the matrix in (b).

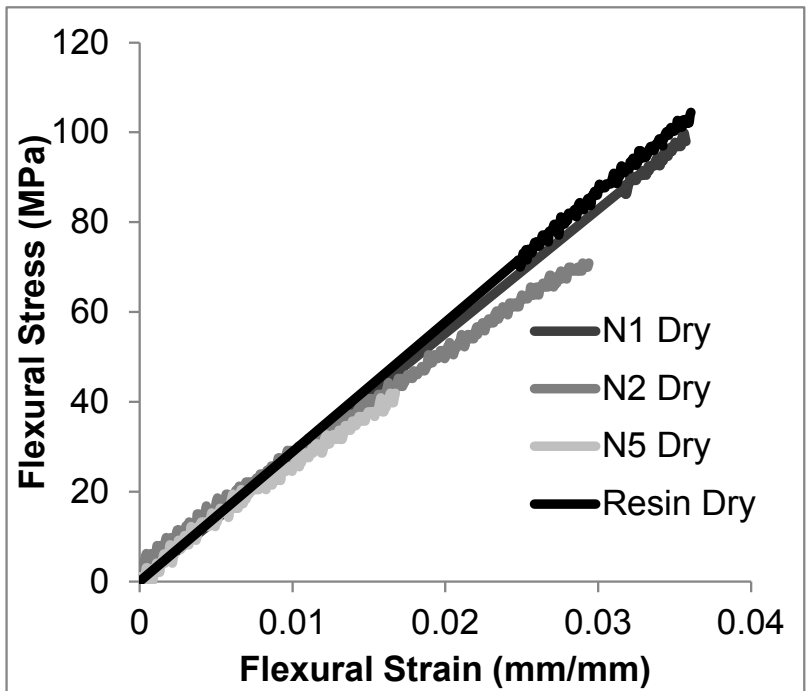

(a)

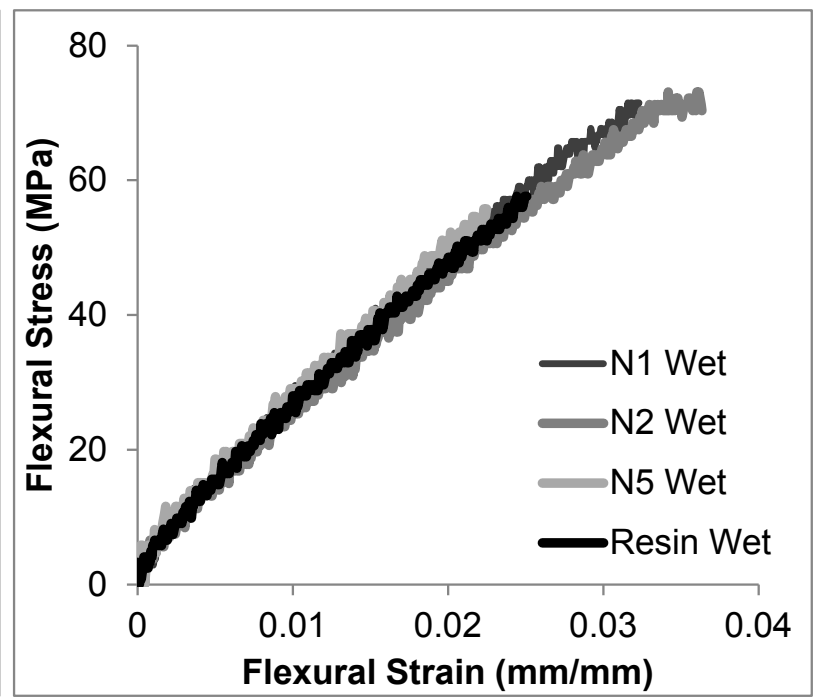

(b)

Figure 8. Representative flexural stress-strain curves of select CNF/epoxy composites and neat epoxy resin under (a) dry and (b) wet conditions. 


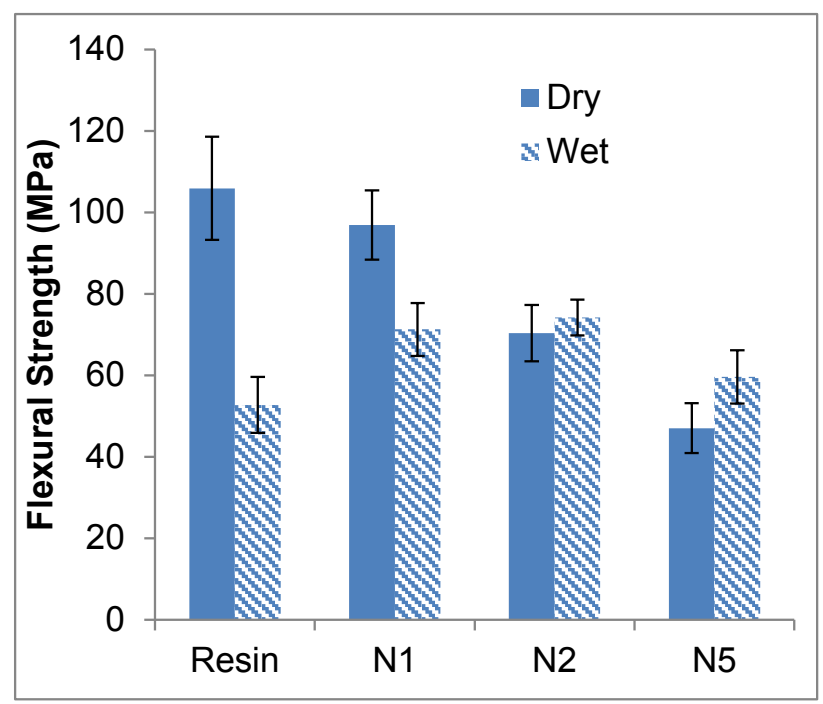

(a)

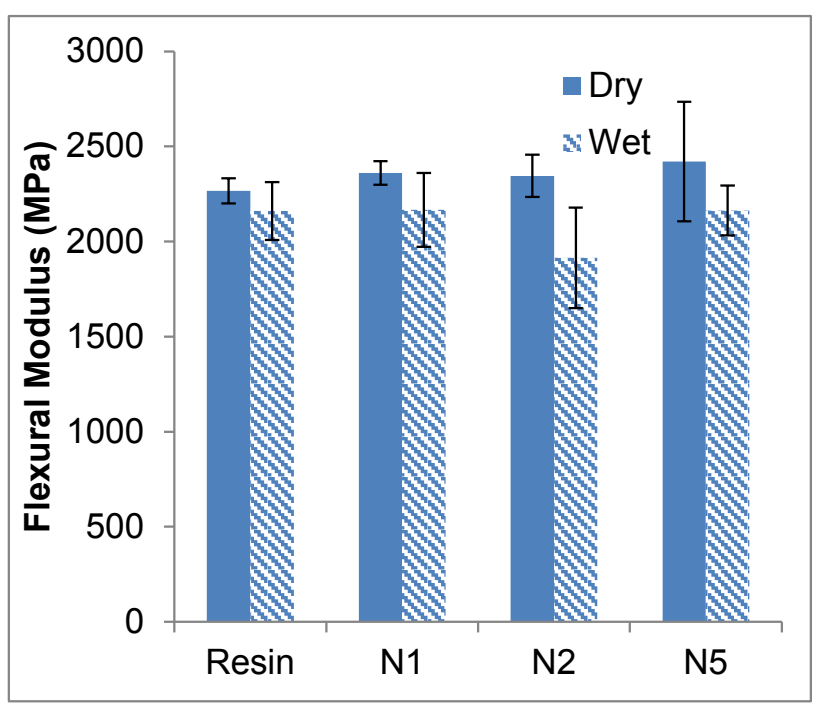

(b)

Figure 9. Comparison of dry and wet (a) flexural strength and (b) flexural modulus of CNF/epoxy composites.

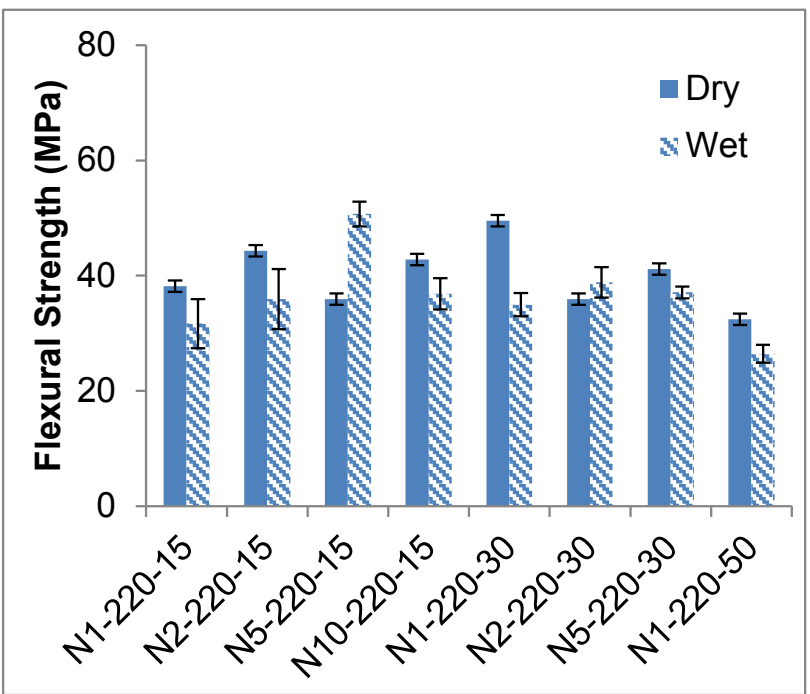

(a)

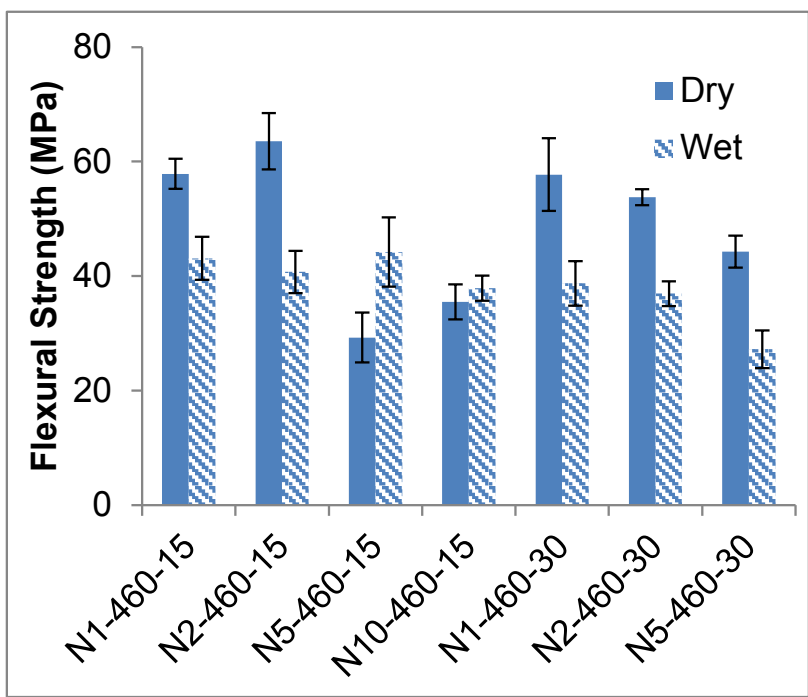

(b)

Figure 10. Comparison of dry and wet flexural strength of CNF/syntactic foams containing GMBs of (a) 220 $\mathrm{kg} / \mathrm{m}^{3}$ and (b) $460 \mathrm{~kg} / \mathrm{m}^{3}$ density. 


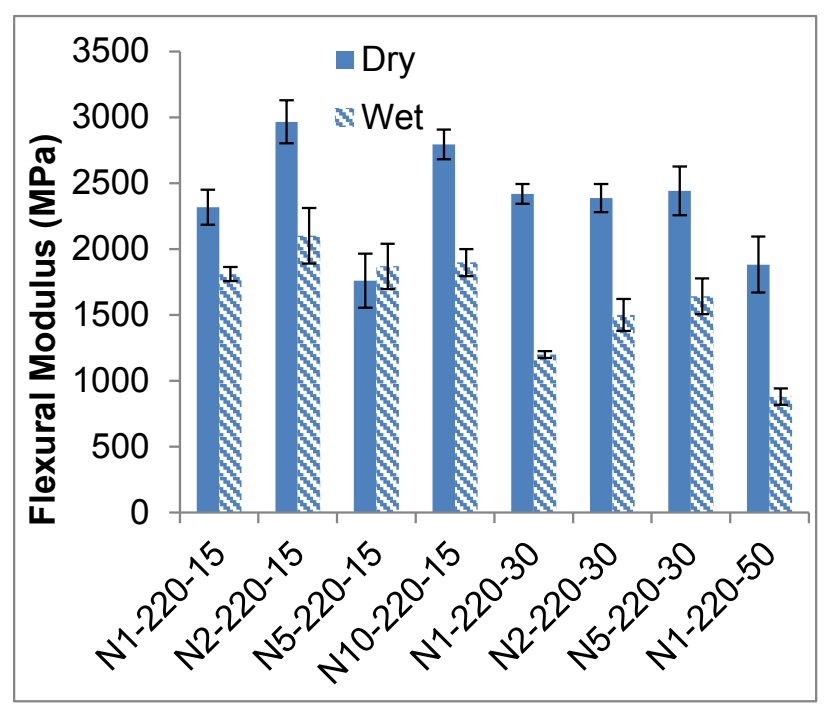

(a)

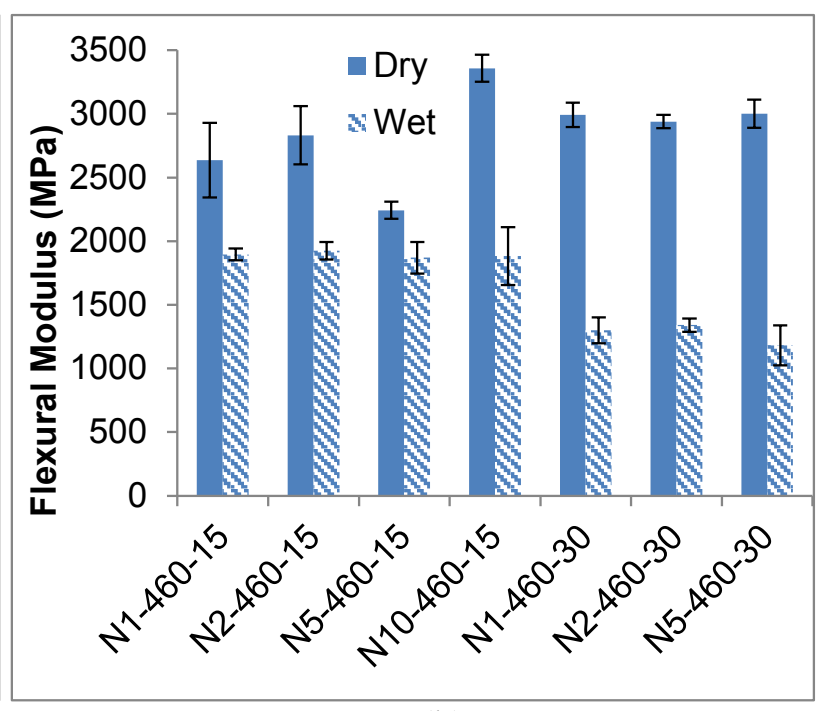

(b)

Figure 11. Comparison of dry and wet flexural modulus of (a) $220 \mathrm{~kg} / \mathrm{m}^{3}$ and (b) $460 \mathrm{~kg} / \mathrm{m}^{3} \mathrm{GMB}$ CNF/syntactic foams.

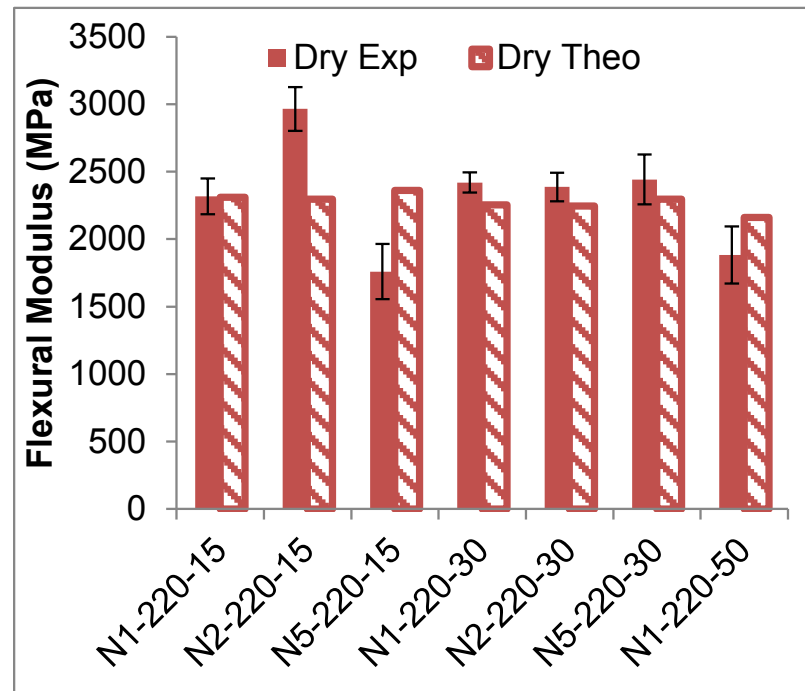

(a)

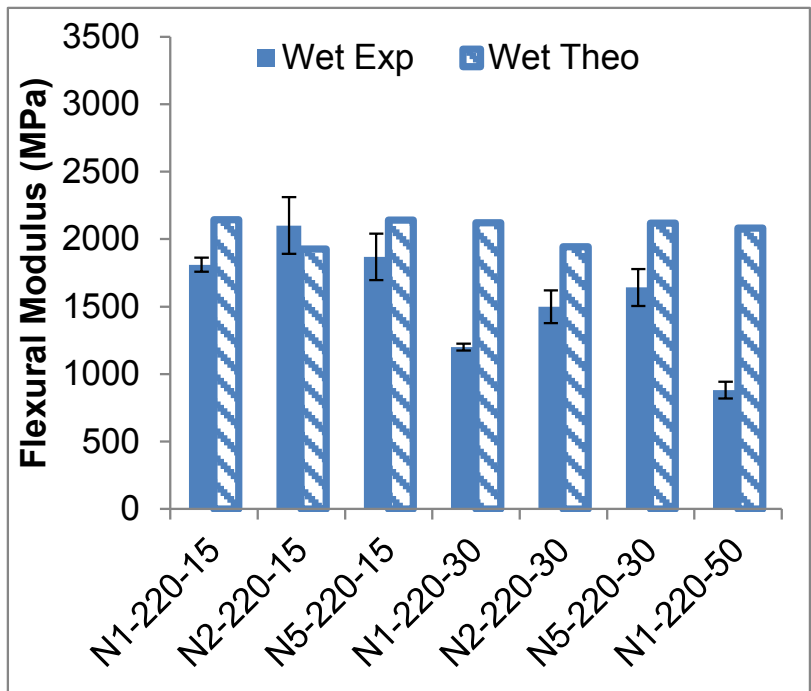

(b)

Figure 12. Comparison of experimental and theoretical flexural modulus of (a) dry and (b) wet CNF/syntactic foams containing $220 \mathrm{~kg} / \mathrm{m}^{3} \mathrm{GMBs}$. 


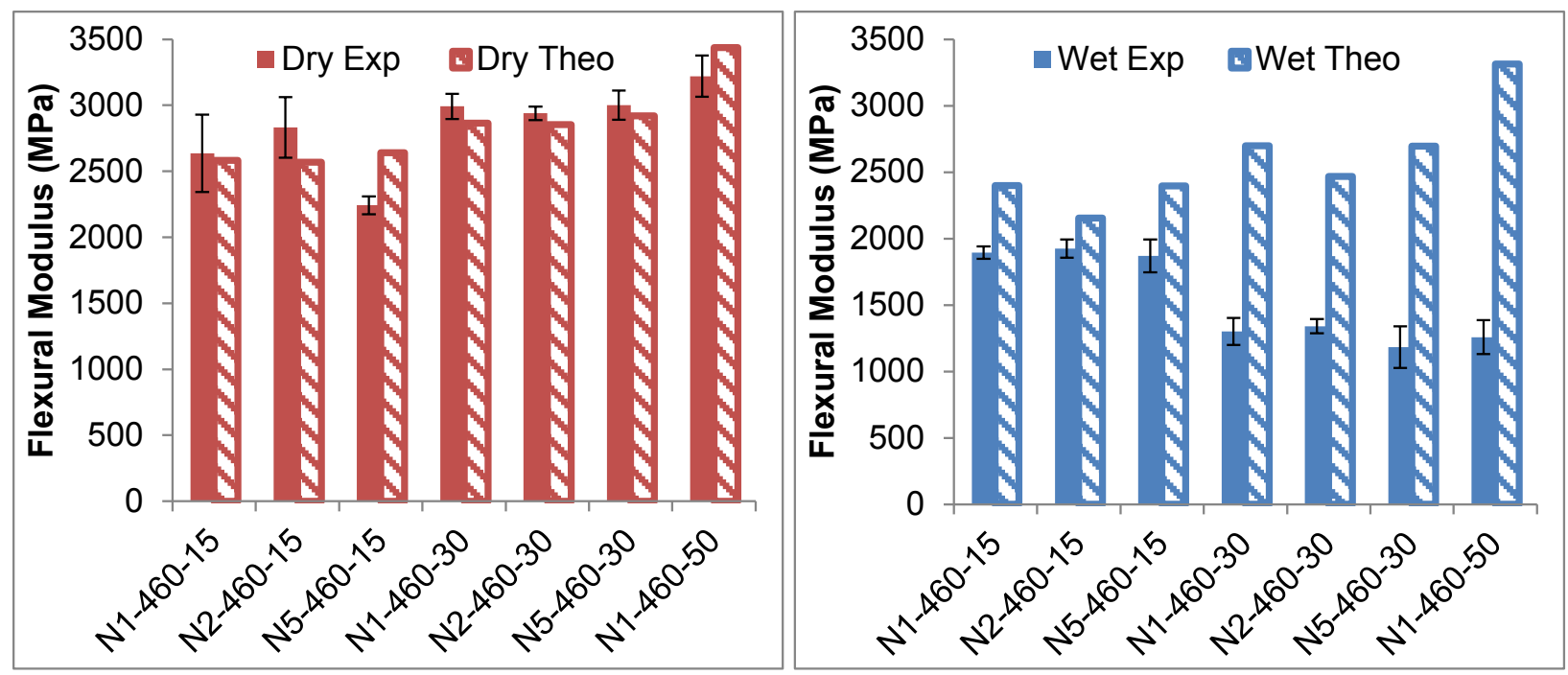

Figure 13. Comparison of experimental and theoretical flexural modulus of (a) dry and (b) wet CNF/syntactic foams containing $460 \mathrm{~kg} / \mathrm{m}^{3} \mathrm{GMBs}$.

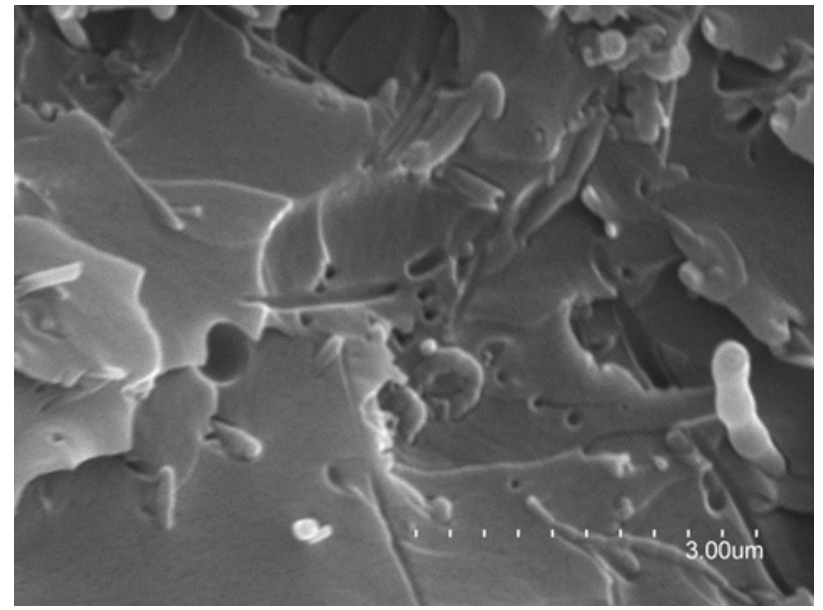

(a)

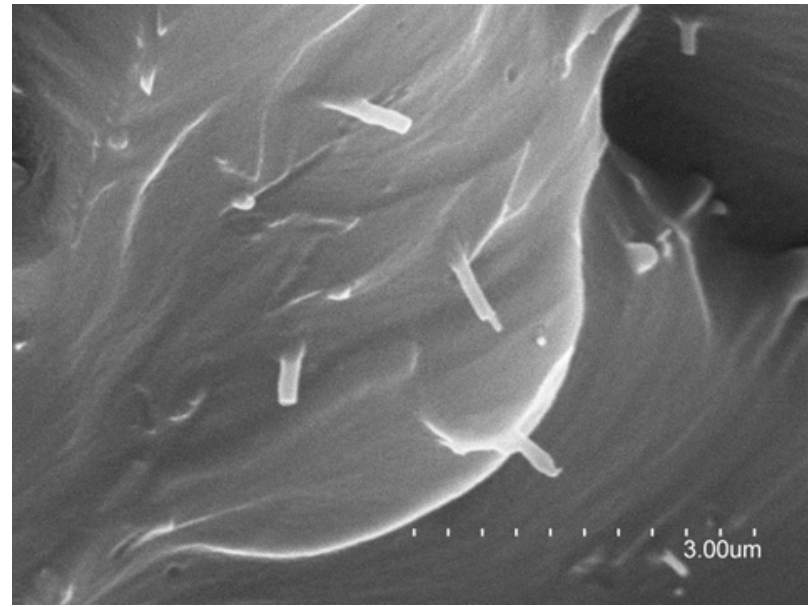

(b)

Figure 14. Comparison of fracture surfaces of (a) wet and (b) dry N5 CNF/epoxy composite. The wet specimens show debonding and fiber pull out. 


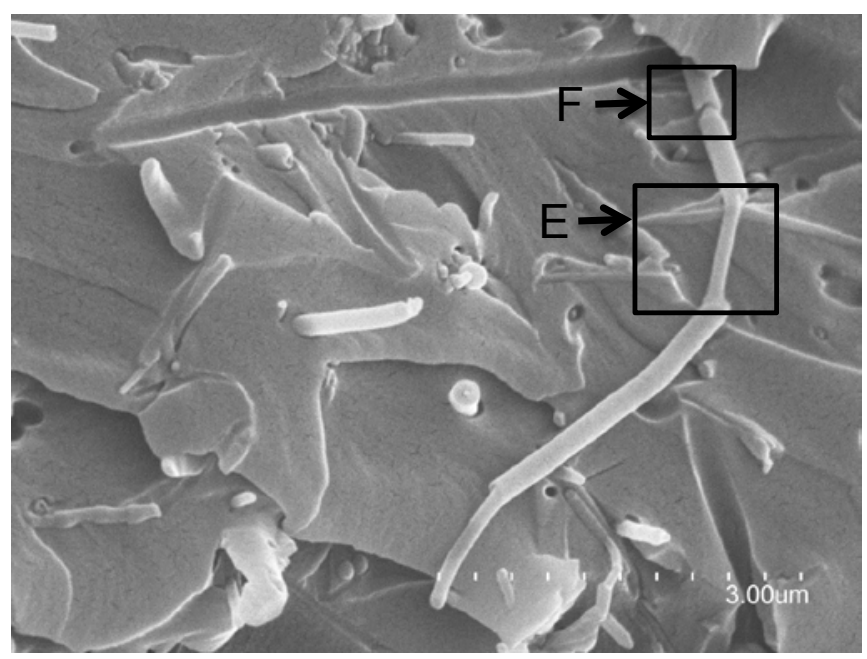

(a)

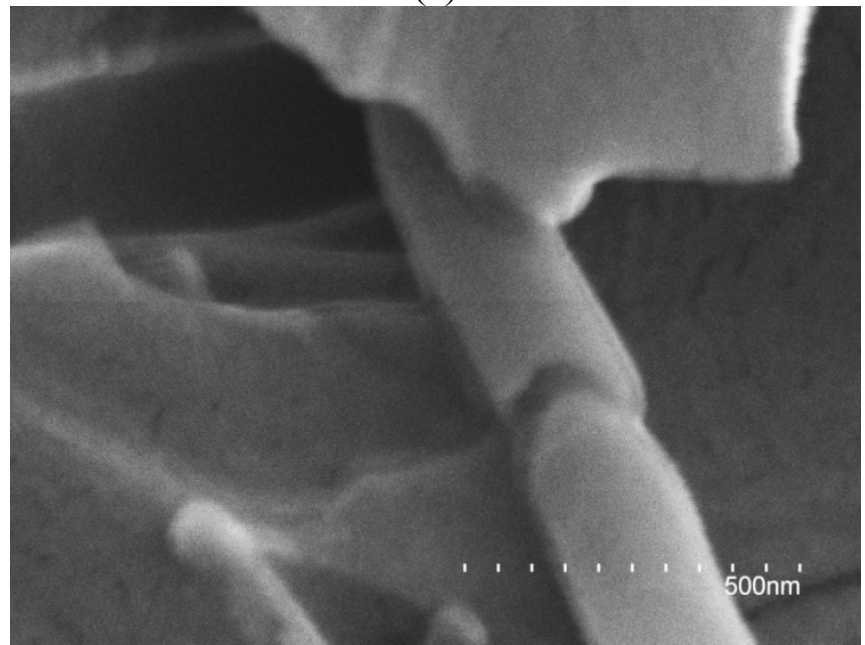

(b)

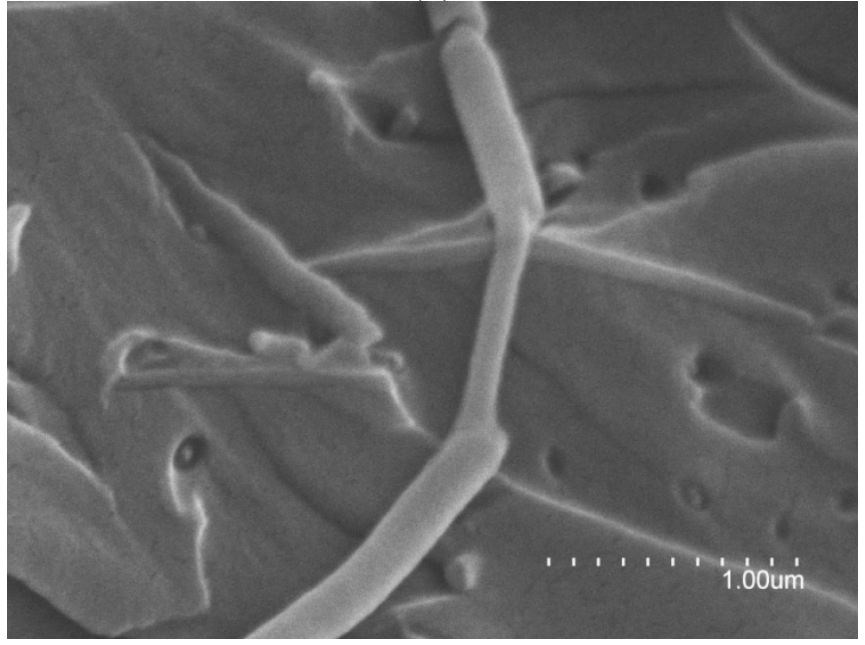

(c)

Figure 15. (a) Debonding of CNFs on fracture surface of N5 CNF/epoxy composite. Region corresponding to box $F$ and $E$ are elaborated in (b) and (c), respectively. (b) Cup and cone type fracture of CNF and (c) fracture of turbostratic carbon layers and sliding over internal graphitic layers. 